\title{
Resveratrol promotes expression of SIRT1 and StAR in rat ovarian granulosa cells: an implicative role of SIRT1 in the ovary
}

Yoshihiro Morita ${ }^{1}$, Osamu Wada-Hiraike ${ }^{1 *}$, Tetsu Yano ${ }^{1}$, Akira Shirane ${ }^{1}$, Mana Hirano ${ }^{1}$, Haruko Hiraike', Satoshi Koyama ${ }^{1}$, Hajime Oishi ${ }^{1}$, Osamu Yoshino ${ }^{1}$, Yuichiro Miyamoto ${ }^{1}$, Kenbun Sone ${ }^{1}$, Katsutoshi Oda ${ }^{1}$ Shunsuke Nakagawa ${ }^{2}$, Kazuyoshi Tsutsui ${ }^{3}$ and Yuji Taketani ${ }^{1}$

\begin{abstract}
Background: Resveratrol is a natural polyphenolic compound known for its beneficial effects on energy homeostasis, and it also has multiple properties, including anti-oxidant, anti-inflammatory, and anti-tumor activities. Recently, silent information regulator genes (Sirtuins) have been identified as targets of resveratrol. Sirtuin 1 (SIRT1), originally found as an $\mathrm{NAD}^{+}$-dependent histone deacetylase, is a principal modulator of pathways downstream of calorie restriction, and the activation of SIRT1 ameliorates glucose homeostasis and insulin sensitivity. To date, the presence and physiological role of SIRT1 in the ovary are not known. Here we found that SIRT1 was localized in granulosa cells of the human ovary.
\end{abstract}

Methods: The physiological roles of resveratrol and SIRT1 in the ovary were analyzed. Immunohistochemistry was performed to localize the SIRT1 expression. SIRT1 protein expression of cultured cells and luteinized human granulosa cells was investigated by Western blot. Rat granulosa cells were obtained from diethylstilbestrol treated rats. The cells were treated with increasing doses of resveratrol, and subsequently harvested to determine mRNA levels and protein levels. Cell viability was tested by MTS assay. Cellular apoptosis was analyzed by caspase 3/7 activity test and Hoechst 33342 staining.

Results: SIRT1 protein was expressed in the human ovarian tissues and human luteinized granulosa cells. We demonstrated that resveratrol exhibited a potent concentration-dependent inhibition of rat granulosa cells viability. However, resveratrol-induced inhibition of rat granulosa cells viability is independent of apoptosis signal. Resveratrol increased mRNA levels of SIRT1, LH receptor, StAR, and P450 aromatase, while mRNA levels of FSH receptor remained unchanged. Western blot analysis was consistent with the results of quantitative real-time RTPCR assay. In addition, progesterone secretion was induced by the treatment of resveratrol.

Conclusions: These results suggest a novel mechanism that resveratrol could enhance progesterone secretion and expression of luteinization-related genes in the ovary, and thus provide important implications to understand the mechanism of luteal phase deficiency.

Keywords: SIRT1, Resveratrol, Ovary, Granulosa cells, Luteinization

\footnotetext{
* Correspondence: osamu.hiraike@gmail.com

'Department of Obstetrics and Gynecology, Graduate School of Medicine,

The University of Tokyo, 7-3-1, Hongo, Bunkyo-ku, Tokyo 113-8655, Japan

Full list of author information is available at the end of the article
} 


\section{Background}

The study of natural compounds with pharmacological activity has become an emerging trend in nutritional and pharmacologic research. Polyphenols represent a vast group of compounds having aromatic ring, characterized by the presence of one or more hydroxyl groups with various structural complexities. Resveratrol (trans-3, 5, 40trihydroxystilbene) is a natural polyphenol synthesized by plants as a phytoalexin that becomes activated under stress conditions such as ultraviolet radiation and fungal infection $[1,2]$. It can be found in berries, nuts and some medicinal plants, and mainly present in the skin of grapes and thus in red wine [3]. Previous studies have reported its anti-oxidant, anti-inflammatory, and growth-inhibitory activities using several cancer cell lines and animal models $[2,4,5]$. These properties of resveratrol have been linked to the inhibition of proliferation in association with cell cycle arrest and apoptotic cell death typically observed in vitro at concentrations in the range of 10$300 \mu \mathrm{M}$ [5-7]. Thus, resveratrol has activity in regulating multiple cellular events associated with carcinogenesis, and the activation of SIRT1 is postulated to be a key event to elucidate the pathophysiology of resveratrol $[8,9]$. SIRT1, the mammalian homologue of yeast Sir2 (silent information regulator 2), functions as an NAD ${ }^{+}$-dependent class III histone deacetylase. SIRT1 deacetylates multiple targets in mammalian cells, including p53, FOXO1, FOXO3, PGC- $1 \alpha$, liver $\mathrm{X}$ receptor, NBS1 and hypoxia-inducible factor $2 \alpha[10,11]$. By regulating these molecules, SIRT1 functions as a master regulator of energy homeostasis, gene silencing, metabolism, genomic stability, and cell survival.

The ability of the ovary to produce growing follicles that ovulate is the basis of female fertilization. A critical feature of ovarian granulosa cell (GC) function is the differentiation of the ovulatory follicle into the corpus luteum which mainly produces progesterone (P4) that is important for the maintenance of pregnancy. Recently, it has been suggested that SIRT1 activator resveratrol plays a role in reproductive biology. Resveratrol was shown to modulate theca cell proliferation [12], and methylated resveratrol analogues possessed biological activities in swine GCs [13]. In the present study, to assess a role of SIRT1 in the regulation of reproductive axis in female, we investigated the expression of endogenous SIRT1 in human and rat GCs and the effect of resveratrol on cellular viability and steroidogenesis in rat GCs.

\section{Methods}

\section{Chemicals}

Diethylstilbestrol (DES) and resveratrol were purchased from Sigma-Aldrich (St. Louis, MO, USA). All other chemicals, unless otherwise mentioned, were obtained from Sigma-Aldrich.

\section{Human cancer cell lines and primary human GCs}

Human cervical cancer cell line HeLa was purchased from American Type Culture Collection (Manassas, VA, USA). Human ovarian granulosa-like tumor cell line KGN, which originated from a Stage III granulosa cell carcinoma in a 63-year-old Japanese women [14], was obtained from RIKEN Cell Bank of Japan (Tsukuba, Japan). Primary human GCs were obtained from patients undergoing transvaginal oocyte retrieval for in vitro fertilization at the University of Tokyo Hospital. The method to purify human GCs was described previously [15]. The study was approved by the Institutional Review Board of the University of Tokyo, and written informed consent for the research use of human GCs was obtained from each patient. These cells were maintained in Dulbecco's modified Eagle Medium (DMEM)/ F12 medium (Invitrogen, Carlsbad, CA, USA) supplemented with $10 \%$ charcoal-stripped fetal bovine serum (FBS; Invitrogen), $100 \mathrm{U} / \mathrm{ml}$ penicillin, $100 \mu \mathrm{g} / \mathrm{ml}$ streptomycin and $0.25 \mu \mathrm{g} / \mathrm{ml}$ amphotericin $\mathrm{B}$ in a humidified atmosphere of $5 \% \mathrm{CO}_{2}$ and $95 \%$ air at $37^{\circ} \mathrm{C}$.

\section{Preparation and culture of rat GCs}

Guidelines for the care and use of laboratory animals as adopted and promulgated by the University of Tokyo were followed. Twenty-three-day-old immature female Wistar rats were purchased from CLEA Japan, Inc. (Tokyo, Japan) and housed in a temperature-controlled room with a $12 \mathrm{~h}$ light $/ 12 \mathrm{~h}$ dark schedule. Pelleted food and water were provided ad libitum. Rats were implanted with SILASTIC capsules (Dow Corning, Corp., Midland, MI, USA) containing $10 \mathrm{mg}$ DES to increase GC number [16], and killed 4 days later by cervical dislocation. Removed ovaries were immediately cleaned of surrounding connective tissues and placed into DMEM/F12 medium supplemented with $10 \%$ charcoal-stripped FBS, $100 \mathrm{U} / \mathrm{ml}$ penicillin, $100 \mu \mathrm{g} / \mathrm{ml}$ streptomycin and $0.25 \mu \mathrm{g} / \mathrm{ml}$ amphotericin B. GCs were harvested by needle puncture of ovarian follicles, suspended in the medium, and purified by filtration with a $100-\mu \mathrm{m}$ cell strainer and then a $40-\mu \mathrm{m}$ cell strainer (BD Biosciences, Bedford, MA, USA). Isolated GCs were washed twice by centrifugation at $200 \times \mathrm{g}$ for $5 \mathrm{~min}$ and cultured in the medium in a humidified atmosphere of $5 \% \mathrm{CO}_{2}$ and $95 \%$ air at $37^{\circ} \mathrm{C}$ [17].

\section{Tissue samples and immunohistochemistry}

The ovarian tissues used in this study were obtained from 5 female patients with regular menstrual cycles who were taking no hormonal drugs and underwent 
radical or extended hysterectomy for carcinoma of the uterine cervix and endometrium. The female patients were 32-44 years old at the time of operation and the operations were performed in proliferative phase of the menstrual cycle. The study was approved by the Institutional Review Board of the University of Tokyo, and written informed consent was obtained in each instance. Immunohistochemistry was performed as described previously [18]. Paraffin sections $(4 \mu \mathrm{m})$ were dewaxed in xylene and rehydrated through graded ethanol to water. Antigens were retrieved by boiling in $10 \mathrm{mM}$ citrate buffer ( $\mathrm{pH}$ 6.0) for $30 \mathrm{~min}$. The cooled sections were incubated in DAKO REAL Peroxidase-Blocking solution (DAKO, Carpinteria, CA, USA) for $30 \mathrm{~min}$ to quench endogenous peroxidase. To block the nonspecific binding, sections were incubated in PBS containing 3\% BSA and $0.5 \%$ Nonidet P-40 for $10 \mathrm{~min}$ at room temperature. Sections were then incubated with the rabbit polyclonal antibody to SIRT1 (sc-15404, Santa Cruz Biotechnology, Inc., Santa Cruz, CA, USA) in DAKO REAL Antibody Diluent (DAKO) overnight at $4^{\circ} \mathrm{C}$. Negative controls were incubated with preimmune serum IgG fraction. ChemMate EnVision Detection system (DAKO) was used to visualize the signal. The sections were developed with 3,3'-diaminobenzidine tetrahydrochloride substrate (DAKO), lightly counterstained with ae's hematoxylin (Wako Chemical, Tokyo, Japan), dehydrated through ethanol series and xylene, and mounted.

\section{Western blotting}

HeLa cells, KGN cells, and human GCs were seeded into 6-cm culture dishes (BD Biosciences) at a density of $1 \times 10^{6}$ cells/dish in $3 \mathrm{ml}$ of the culture medium. After $48 \mathrm{~h}$, the cells were harvested with trypsin $(0.05 \%) /$ EDTA $(0.02 \%)$ and scraped into the lysis buffer containing $50 \mathrm{mM}$ Tris- $\mathrm{HCl}(\mathrm{pH} 8.0), 150 \mathrm{mM} \mathrm{NaCl}$, $0.02 \%$ sodium azide, $0.1 \%$ sodium dodecyl sulfate, $1 \%$ Nonidet P-40, and $0.5 \%$ sodium deoxycholate for 30 min on ice. Rat GCs were seeded into $10-\mathrm{cm}$ culture dishes (BD Biosciences) at a density of $2-3 \times 10^{6}$ cells/ dish in $10 \mathrm{ml}$ of the culture medium. After $48 \mathrm{~h}$, the medium was replaced with fresh medium containing $1 \%$ charcoal-stripped FBS and $100 \mu \mathrm{M}$ of resveratrol, and cell culture was continued. Thereafter GCs were harvested, and lysed. Insoluble material was removed by centrifugation at $12,000 \times \mathrm{g}$, for $20 \mathrm{~min}$ at $4^{\circ} \mathrm{C}$. The supernatants were recovered, and the protein concentrations were measured using Bio-Rad protein assay reagent (Bio-Rad Lab., Hercules, CA, USA). Equivalent amounts of lysate protein (30 $\mu \mathrm{g}$ were subjected to $10 \%$ SDS-PAGE and electrophoretically transferred onto polyvinylidene difluoride membranes (Millipore Corp., Billerica, MA, USA). After blocking nonspecific binding sites by incubation for $1 \mathrm{~h}$ with Tris-buffered saline $(25$
$\mathrm{mM}$ Tris and $150 \mathrm{mM} \mathrm{NaCl}, \mathrm{pH} 7.6)$ containing $5 \%$ nonfat milk and $0.2 \%$ Tween 20 , the membranes were blotted with the primary antibodies overnight at $4^{\circ} \mathrm{C}$. The primary antibodies used were anti-DBC1 [19] and anti-P450 aromatase (P450arom; MCA2077S, AbD serotec, Oxford, UK). Anti-SIRT1 (sc-15404), anti-StAR (sc25806), and anti-LH receptor (LH-R; sc-25828) were purchased from Santa Cruz Biotechnology Inc. (Santa Cruz). Reactive proteins were detected with horseradish peroxidase-conjugated secondary antibodies (Cell Signaling Technology, Inc., Beverly, MA, USA) for $60 \mathrm{~min}$ at room temperature and developed with ECL Plus western blotting detection reagents (GE Healthcare, Little Chalfont, UK). The membranes were stripped with the buffer containing $100 \mathrm{mM}$ 2-mercaptoethanol, 2\% SDS and $62.5 \mathrm{mM}$ Tris- $\mathrm{HCl}$ ( $\mathrm{pH}$ 6.7), then reprobed with mouse monoclonal antibody to $\beta$-Actin (sc-47778, Santa Cruz Biotechnology, Inc.) to confirm equivalent protein loading. The images were scanned by the luminescent image analyzer Image Quant LAS 4000 mini (GE Healthcare).

\section{Granulosa cell progesterone production}

Culture media for the Western blot were collected, frozen, and stored at $-20^{\circ} \mathrm{C}$ until $\mathrm{P} 4$ determination by Progesterone EIA kit (Cayman Chemical Co., Ann Arbor, MI, USA). P4 assay was performed according to the manufacture's instruction. The data are expressed as the amount of steroids $(\mathrm{pg} / \mathrm{ml})$ secreted. The results are representative of three to four independent cultures with each condition in quadruplet.

\section{Cell viability assay}

Viability of rat GCs was examined by using the 3-(4,5dimethylthiazol-2-yl)-5- (3-carboxymethoxyphenyl)-2-(4sulfophenyl)-2H-tetrazolium, inner salt (MTS) assay kit (CellTiter 96 Aqueous One Solution Cell Proliferation Assay; Promega, Madison, WI, USA) according to the manufacturer's instructions. Briefly, cells were seeded into 96-well plates (BD Biosciences) at a density of $1 \times$ $10^{4}$ cells/well in $100 \mu \mathrm{L}$ of the culture medium. After 48 $\mathrm{h}$, the medium was replaced with fresh medium containing 1\% charcoal-stripped FBS and various concentrations of resveratrol, and cell culture was continued for a further $72 \mathrm{~h}$. Resveratrol was dissolved in dimethyl sulfoxide and diluted with the medium to yield desired concentrations. The final concentration of dimethyl sulfoxide never exceeded $0.05 \%$. The effects of resveratrol were investigated at concentrations between 10 and $100 \mu \mathrm{M}$ in consideration of those used in the other studies where resveratrol inhibited the proliferation of various cell types at concentrations in the range of 10-300 $\mu \mathrm{M}$ [5-7]. Finally, the medium was replaced with $100 \mu \mathrm{L}$ of fresh medium containing $20 \mu \mathrm{L}$ of MTS solution and incubated for an additional $4 \mathrm{~h}$. Mitochondrial 
dehydrogenase enzymes of viable cells converted MTS tetrazolium into a colored formazan product. The optical density of samples was read at $490 \mathrm{~nm}$ in the spectrophotometric microplate reader (BioTek, Winooski, VT, USA).

\section{Reverse transcription and quantitative real-time PCR}

Rat GCs were seeded into 6-cm culture dishes (BD Biosciences) at a density of $1 \times 10^{6}$ cells/dish in $3 \mathrm{ml}$ of the culture medium. After $48 \mathrm{~h}$, the medium was replaced with fresh medium containing $1 \%$ charcoalstripped FBS and various concentrations of resveratrol (10-100 $\mu \mathrm{M}$, and cell culture was continued for a further $24 \mathrm{~h}$. Total cellular RNA was extracted using RNeasy Mini Kit (Qiagen, Hilden, Germany) and quantified by measuring absorbance at $260 \mathrm{~nm}$ and stored at $-80^{\circ}$ until assay. The mRNA levels of relevant molecules were measured by quantitative real-time RT-PCR using One Step SYBR PrimeScript RT-PCR Kit (TaKaRa Bio. Inc., Tokyo, Japan) in the Light Cycler (Roche Applied Science, Mannheim, Germany). Accumulated levels of fluorescence were analyzed by the second-derivative method after the melting-curve analysis, and then the expression levels of target genes were normalized to the expression level of $\beta$-Actin in each sample. Primer pairs of analyzed mRNA are described in Table 1.

Table 1 Primer sequences used for quantitative real-time PCR

\begin{tabular}{|c|c|c|c|}
\hline Gene & Primers & Primer Sequence & $\begin{array}{l}\text { Expected } \\
\text { size } \\
\text { in base } \\
\text { pair }\end{array}$ \\
\hline \multirow[t]{2}{*}{$\beta$-actin } & Sense & CGAGTACAACCTTCTTGCAG & 207 \\
\hline & Antisense & TTCTGACCCATACCCACCAT & \\
\hline \multirow[t]{2}{*}{ Bax } & Sense & GAATTGGCGATGAACTGGAC & 157 \\
\hline & Antisense & GCAAAGTAGAAAAGGGCAACC & \\
\hline \multirow[t]{2}{*}{$B C 12$} & Sense & AACATCGCTCTGTGGATGAC & 150 \\
\hline & Antisense & GAGCAGCGTCTTCAGAGACA & \\
\hline \multirow[t]{2}{*}{$D B C 1$} & Sense & TCTCCAAGTCTCGCCTGTG & 158 \\
\hline & Antisense & CTCTGTTGCCTCCAACCAGT & \\
\hline \multirow[t]{2}{*}{$F S H-R$} & Sense & ATGGCCCCCATTTCATTCTT & 82 \\
\hline & Antisense & ACTAGGAGAATCTTGGCCTTGGA & \\
\hline \multirow[t]{2}{*}{$L H-R$} & Sense & ATTGACACTCTGCTTAACTITCCATCT & 82 \\
\hline & Antisense & TGGCCATGAGGTACTCATGATCT & \\
\hline \multirow[t]{2}{*}{ p450arom } & Sense & TCCTCAGCAGAGAAACTGGAAGA & 151 \\
\hline & Antisense & CGTACAGAGTGACGGACATGGT & \\
\hline \multirow[t]{2}{*}{ SIRT1 } & Sense & TGTTTCCTGTGGGATACCTGA & 137 \\
\hline & Antisense & TGAAGAATGGTCTTGGGTCTIT & \\
\hline \multirow[t]{2}{*}{ StAR } & Sense & AGGAAAACAGAACTGAGGCTTAGAATA & 93 \\
\hline & Antisense & AAGGTTTCATAGATACCTGTCCCTTAAC & \\
\hline
\end{tabular}

\section{Caspase-3/7 activity assay}

Apoptosis executioner caspase-3/7 activity in rat GCs was measured using the Apo-ONE Homogeneous Caspase-3/7 Assay kit (Promega) according to the manufacturer's instructions. Briefly, cells were seeded into 96well plates (BD Biosciences) at a density of $1 \times 10^{4}$ cells/well in $100 \mu \mathrm{L}$ of the culture medium. After $48 \mathrm{~h}$, the medium was replaced with fresh medium containing 1\% charcoal-stripped FBS and various concentrations of resveratrol (10- $100 \mu \mathrm{M})$, and cell culture was continued for 6, 12 and $24 \mathrm{~h}$. Caspase-3/7 activity was measured at excitation wavelength $485 \mathrm{~nm}$ and emission wavelength $528 \mathrm{~nm}$ in the spectrophotometric microplate reader (BioTek).

\section{Hoechst 33342 nuclear staining}

Hoechst staining was performed to confirm the apoptotic profile as a result of morphological change in the nucleus in which Hoechst 33342 binds specifically to A$\mathrm{T}$ base region in DNA and emits fluorescence. Rat GCs were seeded into 8-well chamber slides (Nalge Nunc International, Naperville, IL, USA) at a density of $1 \times$ $10^{5}$ cells/well in $400 \mu \mathrm{l}$ of the culture medium. After 48 $\mathrm{h}$, the medium was replaced with fresh medium containing 1\% charcoal-stripped FBS and resveratrol (50 and $100 \mu \mathrm{M})$, and cell culture was continued for $6,12,24$ and $48 \mathrm{~h}$. Finally, cells were rinsed in PBS and fixed with $4 \%$ paraformaldehyde in PBS $(\mathrm{pH} \mathrm{7.4)}$ ) at room temperature for $30 \mathrm{~min}$. Then cells were rinsed in PBS twice and stained with Hoechst $33342(10 \mu \mathrm{g} / \mathrm{ml}$ in PBS) for $3 \mathrm{~min}$. The specimens were mounted with Vectashield medium (Vector Labs. Inc., Burlingame, CA, USA) and photographs were taken at X200 magnification under a fluorescent confocal microscope (CarlZeiss MicroImaging Inc., Oberkochen, Germany).

\section{Statistical analysis}

Data represent the mean \pm SEM from at least three independent experiments. Statistical analyses were carried out by one-way ANOVA with post-hoc test for multiple comparisons by using StatView software (SAS Institute Inc., Cary, NC, USA). $P<0.05$ was considered statistically significant.

\section{Results}

\section{Expression of SIRT1 protein in human GCs}

We investigated the localization of SIRT1 protein in the human ovary using immunohistochemistry. Expression of SIRT1 was observed in nuclei of GCs at various stages of follicular development (Figure 1A-C). Part of the theca interstitial cells and the oocyte were also found to have positive signals. To confirm the expression of SIRT1, luteinized human granulosa cells were obtained from women undergoing in vitro fertilization 

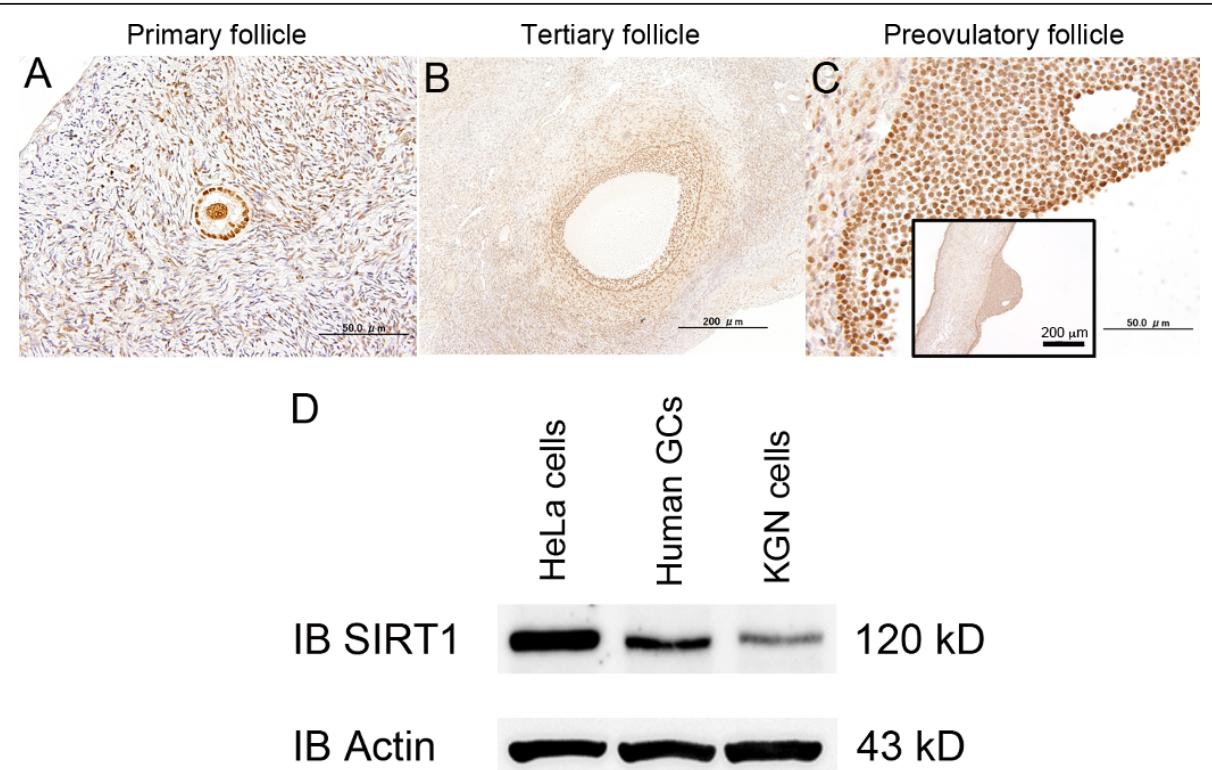

Figure 1 Expression of SIRT1 protein in human GCs. Immunohistochemical detection of SIRT1 in the human ovary (A, primary follicle; B, tertiary follicle; C, preovulatory follicle). Representative data from five specimens were shown. Nuclei of GCs were positively stained with antiSIRT1 antibody at various stages of follicular development. Bars indicate (A) $50 \mu \mathrm{m}$, (B) $200 \mu \mathrm{m}$, and (C) $50 \mu \mathrm{m}$ in high-power field and $200 \mu \mathrm{m}$ in low-power field. SIRT1 was detected in primary (A), tertiary (B), and preovulatory (C) follicles of granulosa cells. Note that a part of the theca cells and oocyte nucleus are stained. Negative controls included a section incubated with preimmune rabbit lgG. (D) Western blotting revealed the presence of SIRT1 in KGN cells, human GCs, and HeLa cells (positive control).

program, and Western blot analysis revealed the expression of SIRT1 protein in KGN cells and human GCs (Figure 1D). HeLa cells were used as a positive control for Western blot because we [19] and other investigators [20] have detected the expression of SIRT1 protein.

\section{Effect of resveratrol on cell viability and expression of SIRT1 and DBC1 in cultured rat GCs}

To determine whether activation of SIRT1 by resveratrol affects rat GC viability, the extent of cell viability was measured by MTS assay. Resveratrol, at concentrations between 50 and $100 \mu \mathrm{M}$, produced a dose-dependent inhibition of cell viability after $72 \mathrm{~h}$ of treatment, with the maximal effect (reduction to $22.8 \pm 4.4 \%$ of the control) being observed at $100 \mu \mathrm{M}$ (Figure 2A). Recent studies have shown that $\mathrm{DBC} 1$ promotes $\mathrm{p} 53$-mediated apoptosis through specific inhibition of deacetylase activity of SIRT1 [21,22]. To determine whether the inhibitory effect on cell viability by resveratrol is related to the change in SIRT1 activation, the effect of resveratrol on mRNA levels of SIRT1 and DBC1, a negative regulator of SIRT1, was investigated by quantitative real-time RT-PCR in cultured rat GCs. After $24 \mathrm{~h}$ culture of rat GCs, mRNA levels of SIRT1 significantly increased at $100 \mu \mathrm{M}$ (Figure 2B), while those of DBC1 remained unchanged (Figure $2 \mathrm{C}$ ). Western blot analysis was also performed to confirm the result of quantitative real time RT-PCR and resveratrol-dependent induction of SIRT1 protein was observed (Figure 2D)

\section{Effect of resveratrol on cell-death machinery in cultured rat GCs}

Resveratrol has been shown to induce cell-cycle arrest and apoptosis in various cell lines [5,12]. To determine whether the reduction of the viability of rat GCs by resveratrol is due to the induction of apoptosis, the effect of resveratrol on mRNA levels of the representative apoptosis promoter $\mathrm{Bax}$ and inhibitor $\mathrm{Bcl}-2$ was analyzed by quantitative real-time RT-PCR in cultured rat GCs at concentrations of resveratrol between 10 and $100 \mu \mathrm{M}$. The significant change in mRNA levels of Bax and $\mathrm{Bcl}-2$ was not found at $24 \mathrm{~h}$ (Figure 3A, B). Apoptosis executioner caspase-3/7 activity was measured in cultured rat GCs at concentrations of resveratrol ranging from 10 to $100 \mu \mathrm{M}$ and at various time points $(6,12$, and $24 \mathrm{~h}$ ). Resveratrol significantly inhibited caspase-3/7 activity at 75 and $100 \mu \mathrm{M}$ after $24 \mathrm{~h}$ of treatment (Figure 3C). Furthermore, the effect of resveratrol on the incidence of apoptotic cells was investigated by Hoechst 33342 nuclear staining. Resveratrol (50 and $100 \mu \mathrm{M}$ ) showed no typical apoptotic changes including nuclear shrinkage, chromatin condensation, and nuclear fragmentation in cultured rat GCs at $6,12,24$, and $48 \mathrm{~h}$ (Figure 3D). 

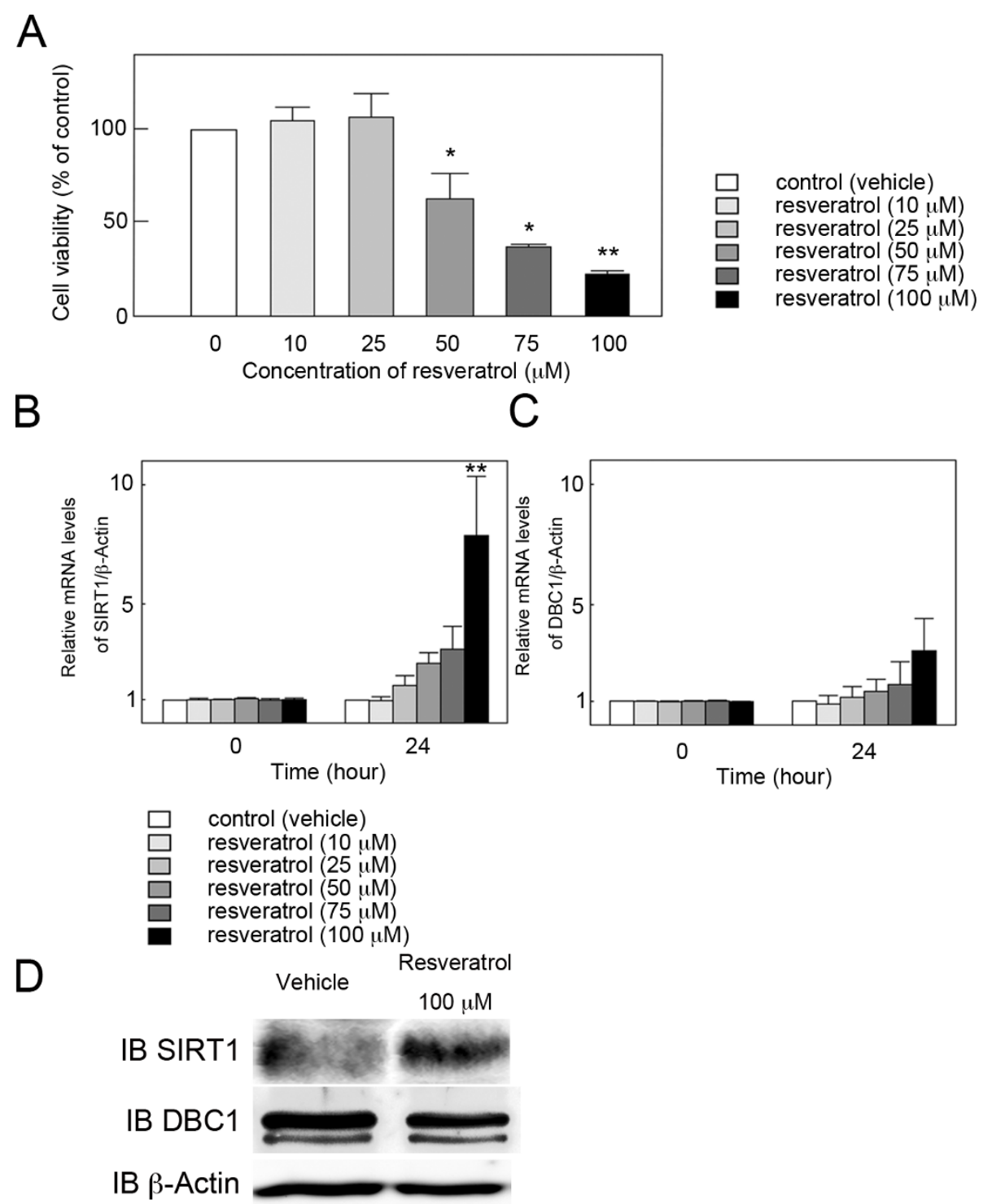

Figure 2 Effect of resveratrol on cell viability and expression of SIRT1 and DBC1 in cultured rat GCs. (A) Effect of resveratrol on cell viability at $72 \mathrm{~h}$ was estimated by MTS assay. Results are shown as the mean percentage of the untreated control \pm SEM (bars) of eight wells of three independent experiments * $p<0.05$ vs. control. ** $p<0.01$ vs. control. (B and C) Effect of resveratrol on mRNA levels of (B) SIRT1 and (C) DBC1 was investigated by quantitative real-time RT-PCR. The mRNA level of the untreated control was arbitrarily set at 1.0, and that of the treatment group was estimated relative to the control value. Results are shown as the mean \pm SEM (bars) of three independent experiments. ${ }^{* *}$ $p<0.01$ vs. control. (D) Effect of resveratrol on protein levels of SIRT1 was investigated by Western blot. Resveratrol treatment resulted in an increased expression of SIRT1 protein, and the results were consistent with that of quantitative real time RT-PCR. Three independent experiments were performed and a representative result is shown.

Effect of resveratrol on folliculogenesis-related molecules in cultured rat GCs

The Effect of resveratrol on mRNA levels of folliculogenesis-related molecules was investigated by quantitative real-time RT-PCR in cultured rat GCs at concentrations of resveratrol between 10 and $100 \mu \mathrm{M}$. After $24 \mathrm{~h}$ culture, resveratrol significantly increased mRNA levels of LH-R, steroidogenic acute regulatory protein (StAR), and P450arom at $100 \mu \mathrm{M}$ (Figure 4B-D), while FSH receptor
(FSH-R) mRNA levels remained unchanged (Figure 4A). Western blot analysis was also performed to confirm the result of quantitative real time RT-PCR and resveratroldependent stimulation of StAR, LH-R, and P450arom protein was confirmed (Figure $4 \mathrm{E}$ ). To investigate the possibility that resveratrol promote steroidgenesis, serum concentration of $\mathrm{P} 4$ was evaluated and it has been revealed that resveratrol exhibited 3-fold enhancement of hormonal secretion at $48 \mathrm{~h}$ of culture (Figure $4 \mathrm{~F}$ ). 


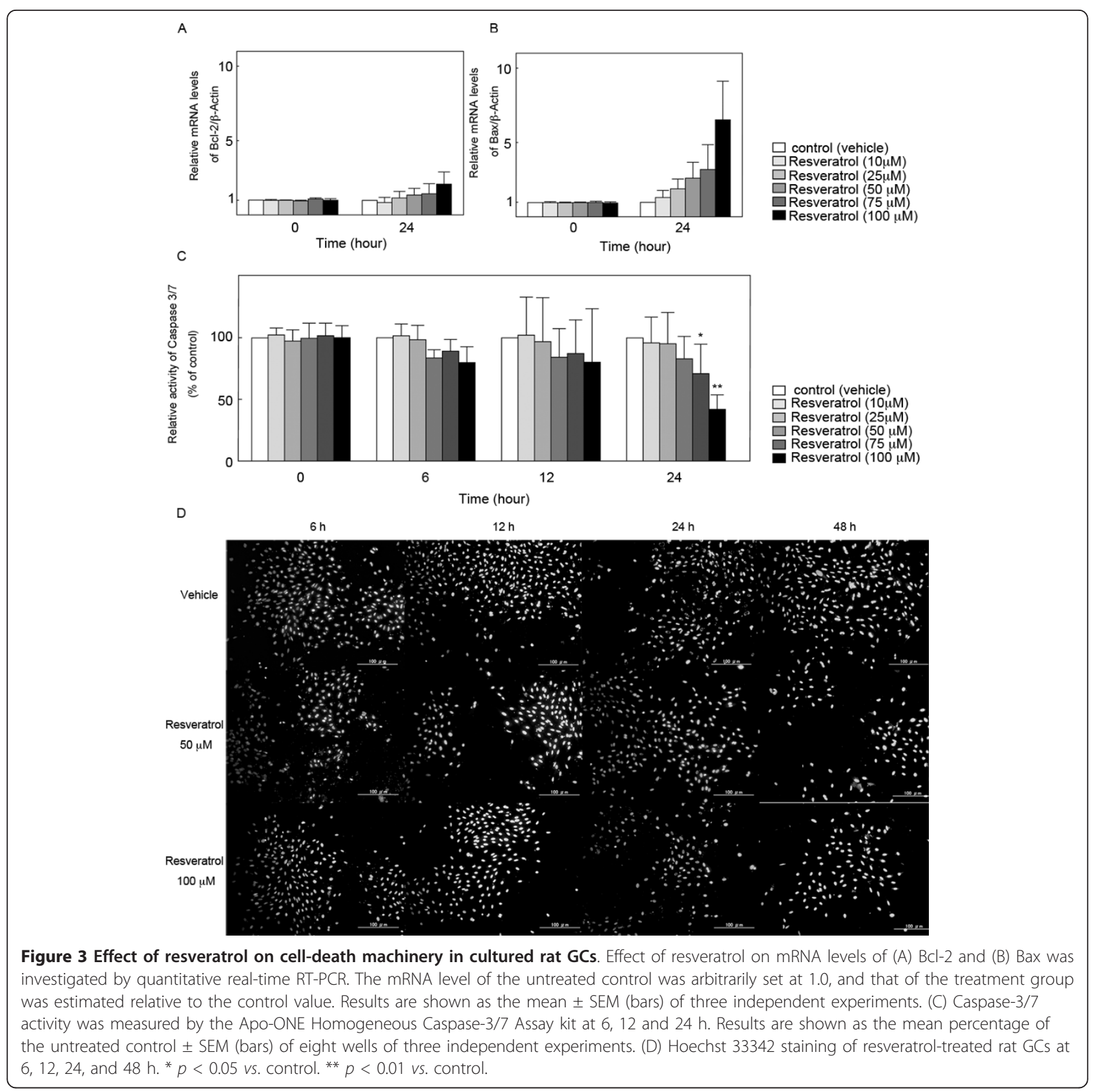

\section{Discussion}

Recently, resveratrol has been the focus of many in vitro and in vivo studies because of its pleiotropic biological activities [1-9]. However, the studies of resveratrol in ovarian physiology are limited. Resveratrol has been reported to exert estrogenic effects, increasing uterine and ovarian wet weight [23]. It is a phytoestrogen known to bind equally to estrogen receptors $\alpha$ and $\beta$ [24], and structurally similar to synthetic estrogens, such as DES and $17 \beta$-estradiol benzoate [25]. In contrast to its hyperproliferative effects, resveratrol promoted apoptosis in rat ovarian theca-interstitial cells [12], and its analogues inhibited swine GC growth [13]. It was also reported that resveratrol inhibited the proliferation of a wide variety of human cancer cell lines through the induction of S-phase cell cycle arrest and apoptosis [5]. In the present study, we demonstrated that resveratrol exerted a dose-dependent inhibition of cell viability on rat GCs. This effect appeared not to be due to the induction of apoptosis, which was different from the previous findings in rat ovarian theca-interstitial cells [12]. Then we studied whether this resveratrol-induced decrease of cellular viability may lead to the differentiation of GCs. 


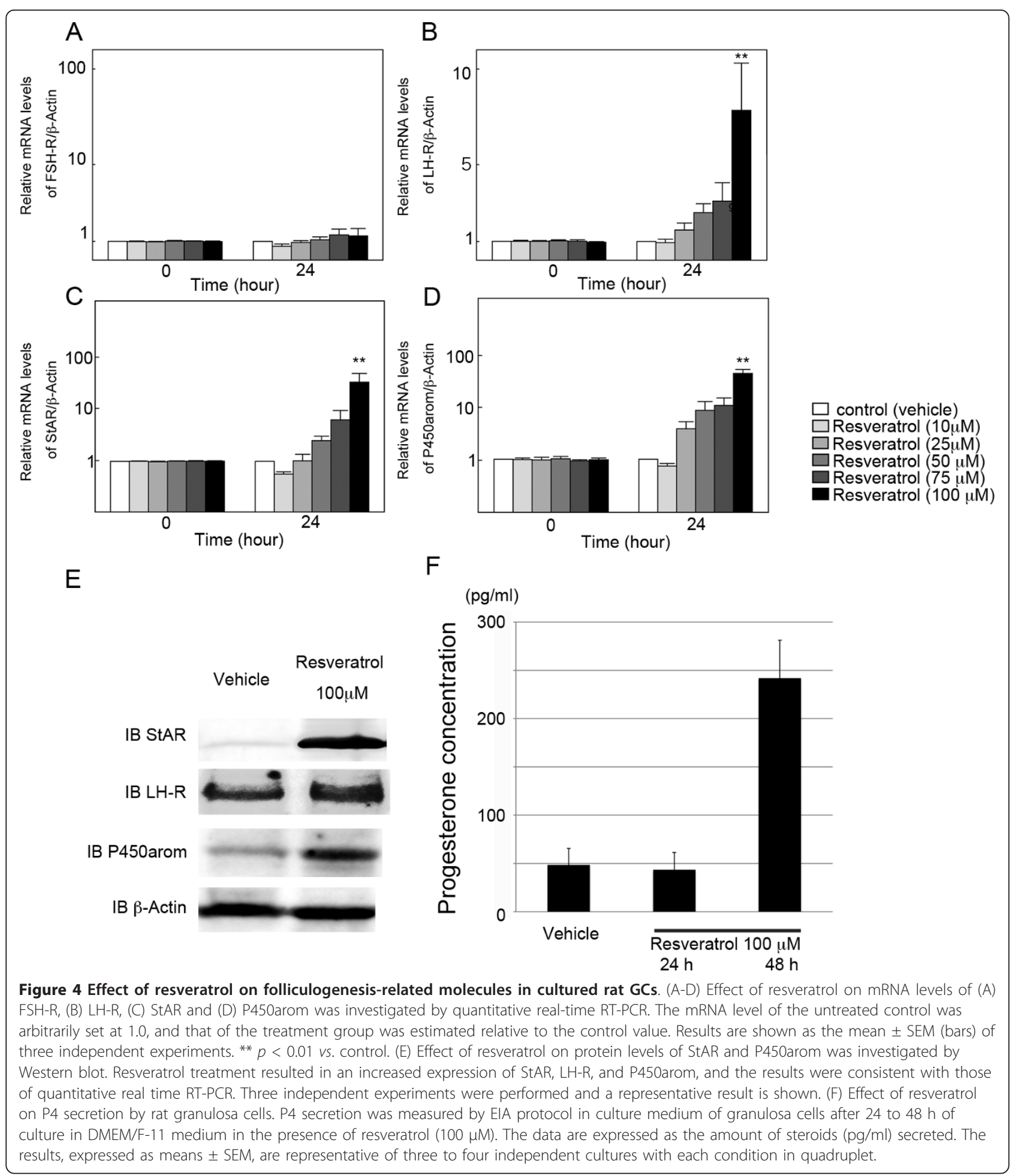

Sirtuins are a conserved family of $\mathrm{NAD}^{+}$-dependent class III histone deacetylases involved in a number of cellular processes including gene silencing at telomere and mating loci, DNA repair, recombination, and aging $[8,10,11]$. Recent studies have established that SIRT1 plays an important role in the regulation of cell fate and stress response in mammalian cells, and promotes cell survival by inhibiting apoptosis or cellular senescence induced by stresses including DNA damage [11]. Indeed, resveratrol administration and accompanying activation 
of SIRT1 has improved health and survival of mice on a high-calorie diet by ameliorating insulin resistance [9]. Here we demonstrated the expression of SIRT1 in human GCs by immunohistochemical and Western blot analysis, and the expression of its mRNA in rat GCs by RT-PCR. To our knowledge, this is the first report that SIRT1 is expressed in the ovarian follicular cells. It is also interesting that resveratrol treatment caused an increase in SIRT1 mRNA levels as well as the stimulation of the deacetylating function of SIRT1. Similar to this result, the mouse experimental model of dextran sodium sulfate-induced colitis was associated with a decrease in SIRT1 gene expression and resveratrol treatment significantly reversed the expression of SIRT1 [26]. However, it should be noted that all actions of resveratrol are not related to the activation of SIRT1 because resveratrol is an indirect activator of SIRT1 and has been shown to activate the expression and activity of nicotinamide phosphoribosyltransferase and AMP-activated protein kinase (AMPK) [27-30].

In our study, resveratrol increased the expression of P450arom and luteinization-related molecules, such as LH-R and StAR, in rat GCs, suggesting a possibility that resveratrol may promote steroidogenesis and luteinization, a process of terminal differentiation of GCs, in the ovary. In fact, P4 secretion was increased after resveratrol treatment. These findings are consistent with the previous study using HL60 promyelocytic cell line [31]. Since mRNA levels of LH-R in the human corpus luteum were reported to be about 7 times higher than those in preovulatory follicles [32], LH-R has been thought to be a key factor in the ability of GC to undergo luteinization. In the human and other primates, StAR is also essential for the development and maintenance of the corpus luteum. StAR is known to govern the rate-limiting step in steroidogenesis, which is the translocation of cholesterol from the outer to the inner mitochondrial membrane [33]. The process of luteinization is associated with up-regulation of StAR in luteinized granulosa cells. Considering the fact that StAR is not highly expressed in GCs of preovulatory follicles [34], our data may implicate a role of SIRT1 and its activator in promoting luteinization of the ovary. Following ovulation, GCs undergo luteinization and form the corpus luteum which secretes P4. Secretion of P4 is indispensable to cause secretory transformation of the endometrium so that implantation can occur. Before the placenta takes over $\mathrm{P} 4$ production, $\mathrm{P} 4$ produced by the corpus luteum provides the necessary support to early pregnancy. A defect in the corpus luteum function is associated with implantation failure and miscarriage [35]. Here we showed a new insight that the resveratrol treatment may serve, at least in part, as luteal support. Physiological roles of resveratrol in the ovary should be further determined because another possible beneficial effect on ovarian physiology is reported. Resveratrol is known as a pure aryl hydrocarbon receptor antagonist with no agonistic activity. Polycyclic aromatic hydrocarbons are environmental toxicants found in cigarette smoke, and stimulate aryl hydrocarbon receptor. Polycyclic aromatic hydrocarbons have detrimental effect on ovarian reserve via inducing Harakiri, and resveratrol may exert its rescuing effect by inhibiting Harakiri expression [36]. However, in view of the significant difference in the ovarian physiology between humans and rodents, our data should be interpreted with caution and the present observations should be verified using human GCs.

\section{Conclusions}

We have demonstrated that resveratrol plays a key role in the activation of luteinization, the terminal differentiation of GCs, and exerts its effects by stimulating the expression of SIRT1, StAR, LH-R, and P450arom in GCs. As a result of these effects, we found that resveratrol promoted P4 secretion. These results suggest that the stimulation of SIRT1 by resveratrol would be potentially beneficial in the treatment of luteal phase deficiency. Several chemical compounds are known to affect the SIRT1 activities, and SIRT1 stimulators are currently extensively investigated for the treatment of diabetes. We hypothesize that these drugs might have a role in ovarian physiology by affecting SIRT1, but further studies are necessary to confirm the physiological implication of SIRT1 in the ovary.

\section{Abbreviations}

DES: Diethylstilbestrol; DMEM: Dulbecco's Modified Eagle Medium; FBS: Fetal bovine serum; FSH-R: Follicle stimulating hormone receptor; GC: Granulosa cell; LH-R: Luteinizing hormone receptor; P4: Progesterone; P450arom: P450 aromatase; RT-PCR: Reverse transcript-polymerase chain reaction; StAR: Steroidogenic acute regulatory protein.

\section{Acknowledgements}

This study was supported by Grant-in-Aid for Scientific Research from the Ministry of Education, Science and Culture, JMS Bayer Schering Pharma Grant, Kowa Life Science Foundation, and Kanzawa Medical Research Foundation, Japan.

\section{Author details}

'Department of Obstetrics and Gynecology, Graduate School of Medicine, The University of Tokyo, 7-3-1, Hongo, Bunkyo-ku, Tokyo 113-8655, Japan. ${ }^{2}$ Department of Obstetrics and Gynecology, School of Medicine, Teikyo University, 2-11-1 Kaga, Itabashi-ku, Tokyo 173-8605, Japan. ${ }^{3}$ Laboratory of Integrative Brain Sciences, Department of Biology, Waseda University, 2-2, Wakamatsuchou, Shinjuku-ku, Tokyo, 162-8480, Japan.

\section{Authors' contributions}

YM carried out all of the experiments. $\mathrm{AS}, \mathrm{MH}, \mathrm{HH}, \mathrm{YM}$, and $\mathrm{KS}$ participated in the immunohistochemistry, real time PCR, Western blot, and hormonal quantification. OY helped to collect and purify rat GCs. SK, MH, and $\mathrm{HO}$ helped to collect human luteinized GCs from follicular aspirates. OW-H has been involved in acquisition of data, drafting the manuscript, and revising it critically for important intellectual content. KO, SN, and TY have made 
substantial contributions to conception and design, analysis and interpretation of data. $\mathrm{KT}$ and $\mathrm{YT}$ have given final approval of the version to be submitted. All authors read and approved the final manuscript.

\section{Competing interests}

The authors declare that they have no competing interests.

Received: 5 September 2011 Accepted: 23 February 2012 Published: 23 February 2012

\section{References}

1. Langcake P, Pryce RJ: A new class of phytoalexins from grapevines. Experientia 1977, 33(2):151-152.

2. Gusman J, Malonne H, Atassi G: A reappraisal of the potential chemopreventive and chemotherapeutic properties of resveratrol. Carcinogenesis 2001, 22(8):1111-1117.

3. Jang M, Cai L, Udeani GO, Slowing KV, Thomas CF, Beecher CW, Fong HH, Farnsworth NR, Kinghorn AD, Mehta RG, et al: Cancer chemopreventive activity of resveratrol, a natural product derived from grapes. Science 1997, 275(5297):218-220.

4. Manna SK, Mukhopadhyay A, Aggarwal BB: Resveratrol suppresses TNFinduced activation of nuclear transcription factors NF-kappa B, activator protein-1, and apoptosis: potential role of reactive oxygen intermediates and lipid peroxidation. J Immunol 2000, 164(12):6509-6519.

5. Joe AK, Liu H, Suzui M, Vural ME, Xiao D, Weinstein IB: Resveratrol induces growth inhibition, S-phase arrest, apoptosis, and changes in biomarker expression in several human cancer cell lines. Clin Cancer Res 2002, 8(3):893-903.

6. van Ginkel PR, Sareen D, Subramanian L, Walker Q, Darjatmoko SR, Lindstrom MJ, Kulkarni A, Albert DM, Polans AS: Resveratrol inhibits tumor growth of human neuroblastoma and mediates apoptosis by directly targeting mitochondria. Clin Cancer Res 2007, 13(17):5162-5169.

7. Issuree PD, Pushparaj PN, Pervaiz S, Melendez AJ: Resveratrol attenuates C5a-induced inflammatory responses in vitro and in vivo by inhibiting phospholipase D and sphingosine kinase activities. FASEB J 2009, 23(8):2412-2424.

8. Howitz KT, Bitterman K, Cohen HY, Lamming DW, Lavu S, Wood JG, Zipkin RE, Chung P, Kisielewski A, Zhang LL, et al: Small molecule activators of sirtuins extend Saccharomyces cerevisiae lifespan. Nature 2003, 425(6954):191-196.

9. Baur JA, Pearson KJ, Price NL, Jamieson HA, Lerin C, Kalra A, Prabhu W, Allard JS, Lopez-Lluch G, Lewis K, et al: Resveratrol improves health and survival of mice on a high-calorie diet. Nature 2006, 444(7117):337-342.

10. Michan S, Sinclair D: Sirtuins in mammals: insights into their biological function. Biochem J 2007, 404(1):1-13.

11. Finkel T, Deng CX, Mostoslavsky R: Recent progress in the biology and physiology of sirtuins. Nature 2009, 460(7255):587-591.

12. Wong DH, Villanueva JA, Cress $A B$, Duleba AJ: Effects of resveratrol on proliferation and apoptosis in rat ovarian theca-interstitial cells. Mol Hum Reprod 2010, 16(4):251-259.

13. Basini G, Tringali C, Baioni L, Bussolati S, Spatafora C, Grasselli F: Biological effects on granulosa cells of hydroxylated and methylated resveratrol analogues. Mol Nutr Food Res 2010, 54(Suppl 2):S236-243.

14. Nishi Y, Yanase T, Mu Y, Oba K, Ichino I, Saito M, Nomura M, Mukasa C, Okabe T, Goto K, et al: Establishment and characterization of a steroidogenic human granulosa-like tumor cell line, KGN, that expresses functional follicle-stimulating hormone receptor. Endocrinology 2001, 142(1):437-445.

15. Shi J, Yoshino O, Osuga Y, Nishii O, Yano T, Taketani Y: Bone morphogenetic protein 7 (BMP-7) increases the expression of folliclestimulating hormone (FSH) receptor in human granulosa cells. Fertil Steril 2010, 93(4):1273-1279.

16. Otsuka F, Moore RK, Wang X, Sharma S, Miyoshi T, Shimasaki S: Essential role of the oocyte in estrogen amplification of follicle-stimulating hormone signaling in granulosa cells. Endocrinology 2005, 146(8):3362-3367.

17. Chen Q, Yano T, Matsumi H, Osuga Y, Yano N, Xu J, Wada O, Koga K, Fujiwara T, Kugu K, et al: Cross-Talk between Fas/Fas ligand system and nitric oxide in the pathway subserving granulosa cell apoptosis: a possible regulatory mechanism for ovarian follicle atresia. Endocrinology 2005, 146(2):808-815.
18. Wada-Hiraike $\mathrm{O}$, Hiraike $\mathrm{H}$, Okinaga $\mathrm{H}$, Imamov $\mathrm{O}$, Barros RP, Morani $\mathrm{A}$, Omoto Y, Warner M, Gustafsson JA: Role of estrogen receptor beta in uterine stroma and epithelium: Insights from estrogen receptor beta-/mice. Proc Natl Acad Sci USA 2006, 103(48):18350-18355.

19. Hiraike H, Wada-Hiraike O, Nakagawa S, Koyama S, Miyamoto Y, Sone K, Tanikawa M, Tsuruga T, Nagasaka K, Matsumoto Y, et al: Identification of DBC1 as a transcriptional repressor for BRCA1. Br J Cancer 2010, 102(6):1061-1067.

20. Kim JE, Lou Z, Chen J: Interactions between DBC1 and SIRT 1 are deregulated in breast cancer cells. Cell Cycle 2009, 8(22):3784-3785.

21. Kim JE, Chen J, Lou Z: DBC1 is a negative regulator of SIRT1. Nature 2008, 451(7178):583-586

22. Zhao W, Kruse JP, Tang Y, Jung SY, Qin J, Gu W: Negative regulation of the deacetylase SIRT1 by DBC1. Nature 2008, 451(7178):587-590.

23. Henry LA, Witt DM: Resveratrol: phytoestrogen effects on reproductive physiology and behavior in female rats. Horm Behav 2002, 41(2):220-228.

24. Bowers $J$, Tyulmenkov W, Jernigan SC, Klinge CM: Resveratrol acts as a mixed agonist/antagonist for estrogen receptors alpha and beta. Endocrinology 2000, 141(10):3657-3667.

25. Gehm BD, McAndrews JM, Chien PY, Jameson JL: Resveratrol, a polyphenolic compound found in grapes and wine, is an agonist for the estrogen receptor. Proc Natl Acad Sci USA 1997, 94(25):14138-14143.

26. Singh UP, Singh NP, Singh B, Hofseth $L$, Price RL, Nagarkatti $M$, Nagarkatti PS: Resveratrol (trans-3,5,4'-trihydroxystilbene) induces silent mating type information regulation-1 and down-regulates nuclear transcription factor-kappaB activation to abrogate dextran sulfate sodium-induced colitis. J Pharmacol Exp Ther 2010, 332(3):829-839.

27. Hou X, Xu S, Maitland-Toolan KA, Sato K, Jiang B, Ido Y, Lan F, Walsh K, Wierzbicki M, Verbeuren TJ, et al: SIRT1 regulates hepatocyte lipid metabolism through activating AMP-activated protein kinase. J Biol Chem 2008, 283(29):20015-20026.

28. Suchankova G, Nelson LE, Gerhart-Hines Z, Kelly M, Gauthier MS, Saha AK, Ido $Y$, Puigserver $P$, Ruderman NB: Concurrent regulation of AMPactivated protein kinase and SIRT1 in mammalian cells. Biochem Biophys Res Commun 2009, 378(4):836-841.

29. Um JH, Park SJ, Kang H, Yang S, Foretz M, McBurney MW, Kim MK, Viollet B, Chung JH: AMP-activated protein kinase-deficient mice are resistant to the metabolic effects of resveratrol. Diabetes 2010, 59(3):554-563.

30. Chung S, Yao H, Caito S, Hwang JW, Arunachalam G, Rahman I: Regulation of SIRT1 in cellular functions: role of polyphenols. Arch Biochem Biophys 2010, 501(1):79-90.

31. Ragione FD, Cucciolla V, Borriello A, Pietra VD, Racioppi L, Soldati G, Manna C, Galletti P, Zappia V: Resveratrol arrests the cell division cycle at S/G2 phase transition. Biochem Biophys Res Commun 1998, 250(1):53-58.

32. Minegishi T, Tano M, Abe Y, Nakamura K, Ibuki Y, Miyamoto K: Expression of luteinizing hormone/human chorionic gonadotrophin (LH/HCG) receptor mRNA in the human ovary. Mol Hum Reprod 1997, 3(2):101-107.

33. Devoto L, Kohen P, Vega M, Castro O, Gonzalez RR, Retamales I, Carvallo P, Christenson LK, Strauss JF: Control of human luteal steroidogenesis. Mol Cell Endocrinol 2002, 186(2):137-141.

34. Kiriakidou M, McAllister JM, Sugawara T, Strauss JF: Expression of steroidogenic acute regulatory protein (StAR) in the human ovary. I Clin Endocrinol Metab 1996, 81(11):4122-4128.

35. Devoto L, Kohen P, Munoz A, Strauss JF: Human corpus luteum physiology and the luteal-phase dysfunction associated with ovarian stimulation. Reprod Biomed Online 2009, 18(Suppl 2):19-24.

36. Jurisicova A, Taniuchi A, Li H, Shang Y, Antenos M, Detmar J, Xu J, Matikainen T, Benito Hernandez A, Nunez G, et al: Maternal exposure to polycyclic aromatic hydrocarbons diminishes murine ovarian reserve via induction of Harakiri. J Clin Invest 2007, 117(12):3971-3978.

doi:10.1186/1477-7827-10-14

Cite this article as: Morita et al:: Resveratrol promotes expression of SIRT1 and StAR in rat ovarian granulosa cells: an implicative role of SIRT1 in the ovary. Reproductive Biology and Endocrinology 2012 10:14. 